\title{
Natural Killer T Cell Based Immunotherapy
}

\section{Priyanka B Subrahmanyam, Wenji Sun, James E East, Junxin Li and Tonya J Webb*}

Department of Microbiology and Immunology, University of Maryland School of Medicine, The Marlene and Stewart Greenebaum Cancer Center, Baltimore, Maryland, USA

\begin{abstract}
Natural killer T (NKT) cells play an important immunoregulatory role and are thought to bridge the innate and adaptive immune responses. Following activation through cognate interactions with lipid antigen presented in the context of CD1d molecules, NKT cells rapidly produce a plethora of cytokines and can also mediate cytotoxicity. Due to their potent effector functions, extensive research has been performed to increase our understanding on how to effectively modulate these cells. In fact, NKT cell agonists have been used as vaccine adjuvants to enhance antigen specific $T$ and $B$ cell responses to infections and malignancy. In this review, we will focus on recent advances in NKT cell-based vaccination strategies. Given the role that NKT cells play in autoimmune disease, infectious diseases, cancer, transplant immunology and dermatology, it is important to understand how to effectively guide their effector functions in order to develop novel immunotherapeutic strategies.
\end{abstract}

\section{Keywords: Vaccines; NKT cells; CD1d}

Abbreviations: Natural Killer T (NKT); Double Negative (DN); Promyelocytic Leukemia Zinc Finger (PLZF); Signaling LymphocyticActivation Molecule (SLAM); Beta ${ }_{2}^{-}$Microglobulin ( $\left.\mathrm{B}_{2} \mathrm{~m}\right)$; a-Galactosylceramide( $\alpha$-Galcer); TCell Receptor(TCR);DendriticCells (Dcs); Hepatitis B Surface Antigen (Hbsag); Major Histocompatibility Complex (MHC); Interferon Gamma (IFN- $)$ ); Antigen Presenting Cells (Apcs); T Helper (Th); Human Immunodeficiency Virus (HIV); Mycobacterium Tuberculosis (Mtb); Mouse Cytomegalovirus (MCMV); Regulatory T Cells (Tregs); Forkhead Box P3 (Foxp3); Toll-Like Receptor (TLR); Lipopolysaccharide (LPS); Nitric Oxide (NO); GraftVersus-Host Disease (GVHD); Programmed Death (PD)-1; Good Manufacturing Practice (GMP)

\section{Natural Killer T Cells}

Natural Killer T (NKT) cells are a lymphoid population distinct from natural killer cells and conventional T cells. NKT cells recognize lipid antigen in the context of CD1 molecules, unlike classical T cells, which recognize peptide antigens presented by MHC class I and class II molecules. Similar to innate immune cells, NKT cells rapidly mediate their effector functions following activation and help activate other immune cells. Type I NKT cells, also known as canonical or invariant NKT ( $i \mathrm{NKT}$ ) cells express a specific TCR $\alpha$ chain rearrangement, namely Va14Ja18 in mice and Va24Ja18 in humans, which is associated with $\mathrm{V} \beta$ chains of limited diversity. Type II NKT cells are CD1d-restricted T cells that express diverse TCRs $[1,2]$. $i$ NKT cells are further classified into $\mathrm{CD}^{+}$and $\mathrm{CD} 4 \mathrm{CD} 8$ double negative $(\mathrm{DN})$ populations in mice [3] whereas human NKT cells are $\mathrm{CD}^{+}, \mathrm{CD}^{+}$or DN [4]. It is thought that $\mathrm{CD} 4^{+}$type I NKT cells produce both $\mathrm{Th} 1$ and $\mathrm{Th} 2$ cytokines such as IFN- $\gamma$ and IL- 4 , respectively, whereas DN type I NKT cells primarily produce Th1-type cytokines [5-7]. Moreover, studies have shown that type I NKT cells exert potent anti-tumor effects, whereas type II NKT cells suppress anti-tumor immune responses through their production of Th2 cytokines, namely IL-4 and IL-13 [8]. This review will focus mainly on canonical, type I $i$ NKT cells.

Similar to conventional T cells, NKT cells develop from CD4 CD8 thymic precursor cells. In contrast to conventional $\alpha \beta \mathrm{T}$ cells, which are selected by MHC-peptide complexes presented by thymic epithelial cells, NKT cells are selected by CD1d-lipid or glycolipid antigen complexes present on the surface of $\mathrm{CD} 4^{+} \mathrm{CD} 8^{+}$double positive cortical thymocytes. In order to develop, NKT cells require signals from the signaling lymphocytic- activation molecule (SLAM) family which is a $70-\mathrm{kDa}$ co-stimulatory molecule belonging to the immunoglobulin (Ig) superfamily [9]. It has been shown that the transcription factor promyelocytic leukemia zinc finger (PLZF) is also essential for NKT cell development [10-12]. Importantly, in the absence of CD1d, NKT cells fail to develop.

\section{CD1 Molecules}

The five members of the human CD1 family (CD1A-E) are encoded on chromosome 1 and are located outside the major histocompatibility complex (MHC) locus [13]. The CD1 proteins are classified into two groups based on amino acid sequence homology: Group 1 contains CD1a, b, c while group 2 contains CD1d. Mice only express CD1d molecules. The CD1 isoforms (CD1a, b, c and d) are assembled in the ER and then sent to the cell surface. Like MHC class I molecules, CD1a, CD1b, CD1c and CD1d heavy chains are transmembrane glycoproteins with three extracellular domains that associate with beta $a_{2}$ microglobulin $\left(\beta_{2} \mathrm{~m}\right)$ for their recognition by $\mathrm{T}$ cells but with varying affinity [14-16]. CD1a-d molecules are expressed on the surface of professional antigen presenting cells such as B cells, macrophages, and dendritic cells as well as a few other cell types. Considering the structural similarity of CD1 to MHC molecules, it is not surprising that $\mathrm{CD} 1$ proteins are antigen presenting molecules [17]. The crystal structures of both mouse and human CD1d have recently been described. These studies have shown that the antigen binding groove of CD1d is deeper, narrower, and extremely hydrophobic compared to MHC class I and class II molecules. The hydrophobic nature of the antigen binding groove is ideal for binding hydrophobic, lipid antigens. In vitro binding studies have determined the molecular mechanism for

*Corresponding author: Tonya J Webb, Department of Microbiology and Immunology and Medicine, University of Maryland School of Medicine, The Marlene and Stewart Greenebaum Cancer Center, Baltimore, Maryland, USA, Tel: 410-7064109; Fax: 410-706-6970; E-mail: twebb@som.umaryland.edu

Received July 06, 2012; Accepted August 17, 2012; Published August 23, 2012

Citation: Subrahmanyam P, Wenji Sun, James East, Junxin Li and Tonya J Webb (2012) Natural Killer T Cell Based Immunotherapy. J Vaccines Vaccin 3:144 doi:10.4172/2157-7560.1000144

Copyright: (c) 2012 Subrahmanyam P, et al. This is an open-access article distributed under the terms of the Creative Commons Attribution License, which permits unrestricted use, distribution, and reproduction in any medium, provided the original author and source are credited. 
lipid antigen presentation by CD1 molecules: the alkyl chains of a lipidligand bind within a highly hydrophobic groove inside the CD1 protein while the polar head group remains exposed on top of the extracellular domain, allowing direct contact with the TCR, leading to NKT cell activation $[18,19]$.

\section{Bacterial Infections}

Since the discovery of NKT cells, there have been relentless efforts to understand their role in the host's immune response to various pathogens $[20,21]$. $\alpha$-Galactosylceramide $(\alpha-G a l C e r)$ is a potent activator of NKT cells [22]. It was discovered during a screen for antitumor reagents derived from the marine sponge Agelas mauritianus [23]. It is now widely used as a synthetic ligand because it activates both human and murine NKT cells. Following treatment with a-GalCer, NKT cells produce cytokines, undergo clonal expansion, and subsequently activate NK cells, dendritic cells, B cells, and T cells [24,25]. $\alpha$-GalCer, the prototypical NKT cell activating ligand, has an $\alpha$-anomeric link between the sugar and the ceramide. This is in contrast to most glycosphingolipids found in nature, making it unlikely that $\alpha$-GalCer is the natural NKT cell activating ligand. Hence there was an urgent search for other activating glycolipids which would implicate a role for NKT cells in anti-bacterial immunity. The first evidence of such a role emerged in 2005, when glycosphingolipids from Sphingomonas, Gramnegative bacteria, were found to activate NKT cells in vitro [26-28]. These bacteria do not contain lipopolysaccharide (LPS), eliminating the possibility of any direct involvement of the Toll-like Receptor (TLR) 4, and supporting the idea of direct bacterial recognition by the NKT cell TCR. It was also found that NKT cells were activated in vivo, following Sphingomonas infection in mice. In addition, Ja $18^{-/-}$mice lacking $i \mathrm{NKT}$ cells had poor clearance of the bacteria from the liver as compared to their NKT cell sufficient counterparts. Following this study, Kinjo et al. reported that diacylglycerols from Borrelia burgdorferi, also Gramnegative bacteria and the causative agent of Lyme disease, could also activate NKT cells [29]. A number of different diacyglycerols were shown to stimulate rapid proliferation of NKT cells and induce strong cytokine production in vivo. The responses could also be correlated to the length and saturation of the acyl chains in these lipids indicating that the responses were directly dependent upon TCR-mediated glycolipid antigen recognition. Together these studies provided the first evidence that NKT cells directly recognize microbial pathogens through their TCR and are important in mounting immune responses to Gram negative bacteria. Thereafter, it was found that the spectrum of NKT cell recognition was broader, and included Gram-positive bacterial pathogens [30]. For example, S. Pneumoniae, known to cause pneumonia and group B Streptococcus, known to cause neonatal sepsis and meningitis can activate NKT cells. Both these pathogens contain diacylglycerol containing glycolipids which bind CD1d and are presented to NKT cells, resulting in their activation. These activated NKT cells respond by cytokine release and are required for bacterial clearance in mice.

Sada-Ovalle et al. have studied the role of NKT cells in Mycobacterium tuberculosis (Mtb) infection [31]. This group reported that Mtb infected macrophages induce strong IFN- $\gamma$ response from splenocytes. This response is CD1d-dependent and can be attributed to NKT cells. Adoptive transfer of NKT cells into mice infected with Mtb resulted in a decreased bacterial burden in the lungs. It was therefore concluded that macrophages present Mtb-associated antigens to NKT cells, which produce IFN- $\gamma$ and eventually lead to killing of these intracellular bacteria. To further extend the observation that NKT cells suppress Mtb replication, mice were treated with the NKT cell activating ligand, $\alpha-G a l C e r$ alone or in combination with isoniazid [32]. It was found that NKT cell stimulation by treatment of Mtb infected mice with a-GalCer led to decreased bacterial burden and longer survival time. This effect was enhanced when $a-\mathrm{C}$-GalCer, a C-glycoside analog of $a-G a l C e r$ was used. This was attributed to the Th1 bias of $a-C-G a l C e r$ as compared to $\alpha-\mathrm{GalCer}$, because IFN- $\gamma$ was reported to play the major role in anti-mycobacterial responses mounted by NKT cells. $\alpha$-GalCer was also found to have an additive protective effect when combined with isoniazid. Macrophage-mediated presentation of bacterial antigens to NKT cells has also been reported in Listeria monocytogenes infection [33]. Emoto et al. reported increased IFN- $\gamma$ and nitric oxide (NO) after intraperitoneal administration of $\alpha-G a l C e r$ in mice infected with $L$. monocytogenes [33]. Infected macrophages thereafter showed increased respiratory burst, which enabled killing of the bacteria. This study indicated that the administration of $\alpha$-GalCer leads to increased bacterial killing in the phagosomes of infected macrophages and also stimulates IFN- $\gamma$ responses by NKT cells, leading to amelioration of listeriosis. It was later reported that accelerated recruitment of $\mathrm{Gr}^{+}$ cells and $\gamma \delta \mathrm{T}$ cells into the liver also contributed to the anti-bacterial effect of $a$-GalCer [34].

The role of NKT cells in various Chlamydial infections has also been studied extensively. Wang et al. reported that pretreatment of mice with $\alpha$-GalCer, followed by genital tract infection with Chlamydia muridarum led to reduced bacterial burden and increased IL-12 and IFN-gamma in the lymph nodes and genital tract [35]. NKT cell stimulation also enhanced IFN- $\gamma$ production by NK cells and $\mathrm{T}$ cells and further boosted the Th1 response to this pathogen. A similar Th1biasing role for NKT cells involving DCs has been established in a murine infection model of Chlamydophila pneumoniae [36]. Besides aiding Chlamydial clearance in mice, NKT cells have also been reported to have a protective role in Chlamydia trachomatis-induced arthritis [37]. CD1d ${ }^{-/-}$mice, which completely lack NKT cells, showed poor local bacterial clearance in the joint and more severe arthritis as compared to wild type controls. Lower IFN- $\gamma$ production and higher regulatory cytokines such as IL- 4 and IL-10 were shown to be the major factors responsible for this differential outcome of infection. All of the above mentioned mouse models utilized C57/BL6 mice and have established a protective role for NKT cells in Chlamydial infections. However Bilenki et al. reported that $\mathrm{CD} 1 \mathrm{~d}^{-/}$mice on a $\mathrm{BALB} / \mathrm{c}$ background had improved outcome after infection with Chlamydia trachomatis and reduced IL-4 and IgE production [38]. Furthermore, treatment of infected mice with $\alpha$-GalCer enhanced bacterial growth in vivo and this could be partially rescued by neutralization of IL- 4 , suggesting that NKT cells exacerbated disease in this setting by skewing toward a Th2 response. Whether this disparity is a result of the mouse strain, which can significantly influence $\mathrm{Th} 1 / \mathrm{Th} 2$ balances, is an issue which remains to be addressed.

Using a different approach to modulate NKT cells in vivo, Devera et al. studied the effect of NKT cell activation on vaccine-induced anti-bacterial immunity to Bacillus anthracis [39]. It was found that administration of $a-G a l C e r$ at the time of immunization led to increased neutralizing antibody titers, as well as a longer duration of protection after immunization with the protective antigen (PA)-based vaccine against Bacillus anthracis. Thus, NKT cells have been shown to play an important role in the immune response to various bacterial pathogens. Moreover, there is significant interest in the modulation of these responses through the use of NKT cell activating ligands alone or in combination with peptide-based vaccines to improve disease 
outcome in various settings.

\section{Viral Pathogenesis}

NKT cells are known to have strong anti-viral activity including direct cytotoxicity [40-42]. In fact, the course of infection with several viruses, including herpes simplex virus (HSV)-1, HSV-2, coxsackievirus B3, lymphocytic choriomeningitis virus, respiratory syncytial virus is altered in mice which lack NKT cells [43-49]. Some viruses, such as HSV, HIV and vaccinia virus, are known to alter CD1d-mediated antigen processing and presentation to NKT cells [41,50-54]. Using a mouse cytomegalovirus (MCMV) infection model, Reilly et al. showed that activation of NKT cells by administration of $\alpha$-GalCer leads to reduced viral titers and increased $\mathrm{CD} 8^{+}$memory $\mathrm{T}$ cells. This study showed that the activation of NKT cells boosted protective immunity to MCMV in mice [55]. Several research groups have reported that Human Immunodeficiency Virus (HIV) infection is associated with reduced numbers of Va24V $\beta 11$ NKT cells in human patients [56-58]. The depletion rate of NKT cells is higher than conventional $\mathrm{CD} 4^{+} \mathrm{T}$ cells, implicating a possible viral immune evasion strategy directed specifically toward NKT cells. NKT cells have also been found to be functionally impaired, with elevated PD-1 expression during chronic HIV-1 infection [59]. Many efforts have been directed towards improving vaccines against HIV by including $\alpha$-GalCer to activate NKT cells. Prominent among these is the work published by Courtney et al. showing that an HIV vaccine based on peptides from the HIV envelope protein gp120, along with $\alpha$-GalCer as an adjuvant could elicit potent immune responses after mucosal delivery [60]. Huang et al. reported improved immunogenicity after co-administration of $a-G a l C e r$ with a DNA vaccine (pADVAX) encoding the Env and Gag proteins of HIV-1 [61]. It was found that $\alpha$-GalCer-mediated activation of NKT cells improved epitope-specific IFN- $\gamma$ responses as compared to the vaccine alone. Moreover, the inclusion of $a-G a l C e r$ also had a dosesparing effect on the DNA vaccine. The activation of NKT cells has also been shown to be important in influenza infection. When compared to wild type controls, $\mathrm{CD} 1 \mathrm{~d}^{-/}$mice are known to have a lower survival rate after influenza virus infection [62]. This effect was attributed to the production of IFN- $\gamma$ by NKT cells which is important for NK cell activation and also for $\mathrm{CD}^{+} \mathrm{T}$ cell responses. IL-22, an inflammatory cytokine important for clearance of bacterial infections, is also thought to be involved in the protective effect of NKT cell activation towards influenza A infection [63]. The inclusion of NKT cell activating ligand a-GalCer in an influenza A vaccine, A/PR/8/34 (PR8) led to increased IgG and $\operatorname{IgA}$ titers [64]. Similarly, pretreatment with formalininactivated PR8 influenza virus in combination with $\alpha$-GalCer resulted in lower viral titers in infected mice and higher PR8 specific antibody titers [65]. Thus, NKT cells are known to play an important role in anti-viral immunity, a fact which is being actively exploited by using NKT cell activating ligands to improve the immunogenicity of vaccines against viral pathogens.

\section{Tumor Immunotherapy}

There is a significant reduction in NKT cell number and function in cancer patients, independent of tumor type or load [66]. NKT cells can mediate direct cytotoxic responses to malignant cells and also modulate anti-tumor immunity by the secretion of various cytokines. An important role for NKT cells in anti-tumor immunity has been well-established and is currently being studied by many research groups [67]. In fact, some of the earliest work in this field involved the administration of $\alpha$-GalCer to mice bearing lung-metastasized B16 melanoma $[68,69]$. Mice treated with $\alpha-G a l C e r$ were found to have strikingly reduced tumor burden as compared to untreated controls. This effect is attributed to the induction of a strong Th1 response; in fact administration of a more Th1 biased analog- $a-C-G a l C e r$, led to even lower tumor burden [70]. Giaccone et al. carried out a phase I trial of direct intravenous injection of $\alpha$-GalCer in patients with advanced cancer in the Netherlands and showed that it was well-tolerated, with no detectable dose-limiting toxicity [71]. Although no objective clinical effects were observed, the authors reported increased serum GM-CSF and TNF- $\alpha$ only in patients with a detectable population of circulating NKT cells. Notably, in clinical trials, the effectiveness of $\alpha$-GalCer in the treatment of tumors has been limited [71]. This is perhaps because systemic injection of $\alpha$-GalCer can cause anergy in NKT cells, at least in mice [72-74].

The development of anti-tumor vaccines has been underway for a long time, but their effectiveness has been limited by poor immunogenicity necessitating high vaccine doses and repeated boosting regimens. Recent research has therefore focused on the use of $\alpha$-GalCer to improve the immunogenicity of these vaccines through the activation of NKT cells. Tumor-specific antigens, such as Hepatitis B surface Antigen (HBsAg) loaded on DCs and adjuvanted with a-GalCer have been shown to cause rapid remission of hepatocellular carcinoma in mice [75]. In situations where tumor-specific antigens remain elusive, autologous tumor-restricted antigens must be used to elicit an immune response. Chung et al. reported that treatment of tumor-bearing mice with lymphoma cells (A20) pulsed with $a-G a l C e r$ enhanced $T$ cell responses [76]. Other types of APCs are also now being studied since the use of $a-G a l C e r$ provides promise in improving the immunogenicity and effectiveness of these anti-tumor vaccines. Therefore, the limited therapeutic efficacy of direct $\alpha$-GalCer administration has led to the development of alternative approaches including targeting antigen-presenting cells, such as dendritic cells, to enhance the activation of NKT cells.

Dendritic cells (DCs) are the most potent subset of antigen presenting cells. The potential to generate DCs from precursors ex vivo under good manufacturing practice (GMP) conditions permits their use for adoptive immunotherapy in the clinic. Due to the finding that mature DCs were more potent than immature DCs for the activation of human NKT cells in vitro [77,78], Chang et al. completed a more

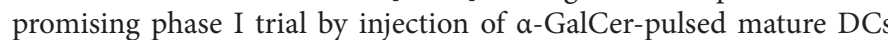
in patients with advanced cancer to test the safety and tolerability [79]. The injections were well-tolerated in all patients, with more than a 100 fold expansion of several subsets of NKT cells even in patients with nearly undetectable levels of NKT cells. Importantly, NKT activation mediated by DCs was sustained, and lasted several months. All of the

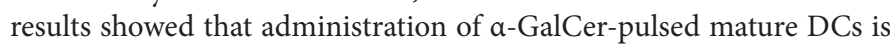
superior to immature DCs or $a-G a l C e r$ alone.

Uchida et al. [80], carried out another clinical trial to test the immunological, safety and clinical responses for the submucosal injection of $\alpha$-GalCer-pulsed DCs in patients with head and neck squamous cell carcinoma. They chose a unique injection route, i.e. nasal submucosa and found that a relatively smaller number of DCs were able to induce significant immune responses. Notably, the authors found increased $i \mathrm{NKT}$ numbers in the peripheral blood compared to intravenous injection. In addition, positive clinical responses and tumor regression without severe side effects were observed for the first time [81]. An exploratory study protocol designed with the preoperative administration of $\alpha$-GalCer-pulsed APCs to treat lung cancer and head and neck cancer patients was carried out by the same group and a significant increase in $i$ NKT cell numbers in the tumor 
microenvironment and augmented IFN- $\gamma$ production by the $\alpha$-GalCerstimulated (tumor infiltrating lymphocytes) TILs were observed [82]. Barral et al. sought to examine the impact of targeting $i$ NKT cell help to antigen-specific $\mathrm{B}$ cells during the development of an immune response [83]. In order to achieve specificity in antigen uptake by B cells, silica beads were coated with liposomes containing 1,2-dioleoyl-sn-glycero3-phosphocholine (DOPC) and biotinyl-phosphatidylethanolamine (PE-biotin) in the presence of a-GalCer. It found that uptake of CD1drestricted antigens by $B$ cells is a tightly-regulated, effective means of enhancing iNKT-dependent B cell responses in vivo. Subsequently, $i$ NKT cells provide the help required for stimulating B cell proliferation and differentiation. Similarly, Bosma et al. recently demonstrated that $\mathrm{B}$ cells are essential for $i$ NKT cell expansion and activation in healthy donors but fail to exert a similar effect in SLE patients [

The activation of $i$ NKT cells by potent agonists, such as $\alpha$-GalCer, results in antitumor responses which is, primarily due to the subsequent activation of NK cells and their production of IFN- $\gamma$. Importantly, NKT cells have been shown to directly mediate lysis of some myelomonocytic leukemia cells, as well as CD1d-transfected tumor cell lines both in vitro and in vivo [85-89]. However, the mechanism by which $i$ NKT cells distinguish CD1d expression on malignant cells from CD1d expression on normal cells remains elusive. It is possible that malignant transformation alters the repertoire of lipid antigens presented by CD1d, but this has not been demonstrated. However, it has been shown that tumors can shed immunosuppressive lipids; which inhibit CD1d-mediated NKT cell responses [90-92]. In addition, DCmediated cross presentation of tumor antigens has been implicated in NKT cell-mediated anti-tumor responses [93,94]. Conversely, it has been proposed that NKT cells may not directly target tumors in vivo, but may control CD1d-expressing tumor-associated macrophages, via blocking these cells from promoting angiogenesis [67].

$i$ NKT cells have been reported to play a protective role in many tumor models, including the methylcholanthrene (MCA)-induced fibrosarcomas, in p53 deficiency and in the transgenic adenocarcinoma of the mouse prostate (TRAMP) prostate cancer model, by comparing Ja18-deficient (which specifically lack $i$ NKT cells) and CD1d-deficient mice (which lack both type I and type II NKT cells) to wild type control mice [95-98]. In mice, tissue specific differences have been described for NKT-mediated anti-tumor responses. Specifically, it was found that liver NKT cells were more important for anti-tumor responses, compared to NKT cells isolated from the thymus and spleen [99]. In contrast to type I NKT cells, type II NKT cells have been shown to suppress the tumor immune surveillance provided by $i \mathrm{NKT}$ cells, which may help explain the paradox in the role of CD1d-restricted T cells in the regulation of tumor immunity $[86,100]$.

Adoptive immunotherapy involves stimulation of tumor specific $\mathrm{T}$ cells, ex vivo, followed by transfer of expanded numbers of activated autologous T cells back into patients. Va24+ ${ }^{+} \mathrm{NKT}$ cells can be expanded by repeated stimulation of peripheral blood mononuclear cells with a-GalCer in vitro, even when the frequency of circulating NKT cells is verylow. Importantly, these cells retain their original phenotype, produce cytokines, and display cytotoxic function against tumor cell lines, and therefore can be used for adoptive immunotherapy. Motohashi et al. [101] performed an adoptive transfer of in vitro activated NKT cells in patients with lung cancer that was refractory to standard treatment regimens. After two infusions of $\alpha$-GalCer-expanded enriched $i$ NKT cells, the frequency of circulating NKT cells was increased in two out of three patients. More specifically, an augmentation of IFN- $\gamma$ producing cells in PBMCs was detected, with most of them showing an NK phenotype $\mathrm{CD}^{-} \mathrm{CD}^{-} 6^{+}$. Therefore, in vitro a-GalCer-activated NKT cells can be used to further stimulate NK cells to produce IFN- $\gamma$, which has been critically linked to anti-tumor immune responses in preclinical studies. Kunii et al. [102] carried out another clinical trial in combination with the intra-arterial infusion of activated Va24 NKT cells and the submucosal injection of $a-$ GalCer-pulsed APC. This strategy has been shown to induce significant antitumor immunity and had beneficial clinical effects in the management of advanced head and neck squamous cell carcinomas (HNSCC). However, these regimens still need to be refined because of the high variability of NKT cell frequency in humans, and new structural analogues may be found to selectively activate different NKT cell subsets.

\section{NKT Cells in Dermatology}

NKT cells have been shown to play an active role in skin diseases, such as contact sensitivity. They have also been implicated in UVinduced immunosuppression and psoriasis [103,104]. Langerhans cells have been shown to activate NKT cells during UV damage. Once activated by Langerhans cells, the NKT cells are capable of producing IL-4 and are immunosuppressive [105,106]. Another study has shown the immunosuppressive characteristics of NKT cells in skin cancer models [107]. Dendritic cells are known to play a role in contact hypersensitivity (CHS), a well-studied form of T cell mediated immunity. CD1d-restricted NKT cells were also shown to be an important part of this process as CD1d knockout mice as well as wild type mice treated with NKT antagonists showed a marked reduction in CHS responses [108]. Correspondingly, NKT are important mediators of contact sensitivity (CS) through secretion of IL-4 and downstream activation of B-1 cells [109]. A recent study of the phenotype and function of naïve and memory $\mathrm{CD}^{+}$and $\mathrm{CD}^{+} \mathrm{T}$ cells, as well as regulatory $\mathrm{T}$ cells and NKT cells in non-segmental vitiligo (NSV), which results from the autoimmune destruction of melanocytes [110]. It was found that the percentage of circulating NKT cells was significantly reduced in their cohort of $43 \mathrm{NSV}$ patients, compared to matched-healthy volunteers, suggesting a role for NKT cells in controlling the pathogenesis of this disease. Taken together these studies suggest that over expression of CD1d in the skin can lead to aberrant NKT cell activation, resulting in disease. Thus, the development of topical agents which can locally suppress their function may be an advantageous therapeutic strategy. However, the reduction of NKT cells in the peripheral blood of patients with autoimmune diseases, such as NSV, suggests that NKT cells play an important role in the context of immunoregulation, as discussed below.

\section{Autoimmunity}

NKT cells are important regulatory lymphocytes that have been reported to suppress cell-mediated autoimmunity. Conversely, aberrant activation of NKT cells has also been linked to the development of autoimmunity [2]. Defects in NKT cells have been correlated with increased incidence of autoimmune diseases such as type I diabetes, multiple sclerosis, systemic lupus erythematous, rheumatoid arthritis $[111,112]$. The most controversial association between NKT cell defects and autoimmune diseases has been reported for type I diabetes. For example, NKT cell frequency and cytokine production are defective in NOD mice [113], and adoptive transfer of NKT cells or over-expression of NKT cell TCR can reverse established diabetes [114-116]. Moreover, over-expression of CD1d or stimulation of NKT cells with $\alpha$-GalCer prevents the development of diabetes in NOD mice [113,117]. Similar phenomenon, such as decreased circulating NKT cell frequency, decreased IFN- $\gamma$ and IL-4 production have been reported in humans with diabetes [118], but these alterations may be restricted to particular NKT cell subsets [119]. 
Several groups have investigated the possibility of activating NKT cells in order to alleviate type I diabetes in NOD mice. Results show that repeated injection of $\alpha$-GalCer can consistently protect against the development of diabetes, even in mice with significant insulitis $[113,120]$. The protection was associated with a shift in cytokine profile of islet-specific T cell responses from Th1 to Th2 bias [113,121]. Another group showed an important role of $\mathrm{CD}^{+} \mathrm{CD} 25^{+} \mathrm{FoxP} 3^{+}$regulatory $\mathrm{T}$ cells in the capacity of $\alpha$-GalCer to protect NOD mice against diabetes [122]. Overall, these studies demonstrated that NKT cells play a key role in protection against diabetes in NOD mice through multiple pathways.

\section{NKT Cells in Inflammation}

NKT cells have been implicated in a number of inflammatory processes including eosinophilic esophagitis [123], asthma [124], peritonitis [125], liver and adipose tissue inflammation [126]. However, it should be noted that the absolute relationship between NKT cells and inflammation is not completely clear because as has been reported for autoimmunity, NKT cells are sometimes involved in the reduction of inflammation [127]. The molecular mechanisms involved in NKT cellmediated inflammation are still unclear. In models of esophagitis, it is clear that IL-15 is important for both NKT cell survival and proliferation. In fact, transcripts of this cytokine are found in high quantities in the esophagus [123]. Due to their unique ability to produce both Th1 and Th2 cytokines, NKT cells are well-suited to regulate inflammatory responses.

NKT cells are known to be stimulated by excess dietary lipids in an obese mouse model [128]. This NKT cell stimulation is responsible for an increase in proinflammatory cytokine production. Further downstream, other leukocytes are eventually biased towards an inflammatory cytokine profile and perpetuate this response. This effect was not seen in mice where the NKT cell population had been deleted. Additionally, the administration of synthetic lipid antigens which bind to CD1d molecules resulted in increased lung inflammation and airway hyper reactivity in mice [127].

\section{Transplant Immunology}

While some studies suggest that NKT cells play a role in the immune response to transplants, it is not clear whether NKT cells directly recognize alloantigens in the context of CD1d molecules or if they are activated during transplantation by the cytokine milieu generated by non-specific inflammation. In addition, the presentation of iGb3, or other yet to be identified glycolipids, following tissue damage may promote CD1d-dependent activation of NKT cells. Therefore, NKT cells may promote rejection or tolerance depending on their response to these antigens. In rat models of liver transplantation, animals treated with $\alpha$-GalCer showed much higher allograft survival compared to control, saline-treated animals. Th2 associated IL-10 cytokine production was much higher in $\alpha-G a l C e r$ treated animals versus control while the induction of IFN- $\gamma$ was much lower as assessed by RT-PCR and ELISA [129]. CD4 ${ }^{+}$NKT cells also play an essential role in pancreatic islet xenotransplantation [130]. IFN- $\gamma$ appears to play a major role in the immunosuppressive abilities of NKT cells in cardiac allograft models in mice, as IFN- $\gamma$ knockout mice have much shorter transplant tolerance time [131]. NKT cells have been shown to promote transplant tolerance in combined heart and bone marrow recipients through their induction of IL-10 production by Tregs [132]. This IL-10 mechanism of transplant tolerance has been shown to be important in the prevention of graft-versus-host disease (GVHD) $[133,134]$. Programmed death (PD)-1 expression in the process is upregulated on Tregs as well as classic $\mathrm{CD} 4^{+}$and $\mathrm{CD} 8^{+} \mathrm{T}$ cells following
NKT cell production of IL-4. Lan et al. developed a non myeloablative host conditioning regimen in a mouse model of MHC-mismatched bone marrow transplantation able to reduce radiation toxicity, as well as afford protection against GVHD. It was demonstrated that protection was due to $\mathrm{NK} 1.1^{+}$and $\mathrm{DX}^{+}$asialo-GM1 ${ }^{+} \mathrm{T}$ cells derived from either donors or hosts conditioned with lymphoid irradiation is dependent on their secretion of high levels of IL-4 [135]. Similarly, Zeng et al. reported a specific role for IL- 4 production by NKT cells in mediating protection from GVHD [136]. Specifically, it was found that bone marrow derived NK1.1 ${ }^{+} \mathrm{T}$ cells obtained from $\mathrm{IL}-4^{-/-}$rather than wild-type C57BL/6 donors not only failed to prevent GVHD but actually increased its severity. In some cases, NKT cells may play a role in increased inflammation and graft rejection. It has been reported that human lung transplant recipients can have a six-fold increase in their NKT population post-transplant compared to healthy donors [137]. A negative correlation between IL-17A producing NKT cells and timepost transplant was seen in this same study indicating a link between NKT cell population and early rejection. There is a spectrum of NKT cell agonists reported in the literature but there are three well-characterized glycolipid antigens routinely used to modulate NKT cell function: a-GalCer-induces both Th1 and Th2 cytokines [138], C-GalCer-Th1 bias [139], and $\mathrm{OCH}$, a sphingosine truncated derivative of alphagalactosylceramide, -Th2 bias [140]. These molecular tools have been used to improve outcomes in models of transplantation. $\mathrm{OCH}$, in conjunction with the immunosuppressant rapamycin, demonstrated improved survival in murine models of heart transplantation [141]. This increase in survival was correlated with increased levels of IL-4, IL-10 and IL-13; all part of a Th2 phenotype. Th1 cytokines derived from NKT cells stimulated by $\alpha$-GalCer seem to promote poor outcomes in GVHD models in mice [142].

\section{Summary}

NKT cells play a pivotal role in maintaining immune homeostasis, due to their unique ability to rapidly produce cytokines that activate cells of both the innate and adaptive immune responses following cognate recognition of lipid antigen presented in the context of CD1d. The ability to precisely modulate these cells in order to enhance vaccination strategies is an intriguing possibility. Novel lipid antigens have been discovered, which can preferentially skew NKT cell-mediated responses towards either a Th1 or Th2 bias. Studies from our group are focused on investigating the use of different lipid antigens in combination with specific co-stimulatory molecules in order to effectively modulate NKT cells for cancer immunotherapy. Furthermore, non-small molecule based specific of NKT cell specific modulation are currently being investigated $[124,125]$. These studies provide a potential platform for modulating NKT responses in vivo. While the mechanisms which dictate whether the in vivo activation of NKT cells will contribute to the establishment of long-term memory responses is unknown, it is clear that more studies need to be done in order to increase our understanding of this potent effector $\mathrm{T}$ cell subset.

\section{References}

1. Godfrey DI, MacDonald HR, Kronenberg M, Smyth MJ, Van Kaer L (2004) NKT cells: what's in a name? Nat Rev Immunol 4: 231-237.

2. Berzins SP, Smyth MJ, Baxter AG (2011) Presumed guilty: natural killer T cell defects and human disease. Nat Rev Immunol 11: 131-142.

3. Terabe M, Berzofsky JA (2008) The role of NKT cells in tumor immunity. Adv Cancer Res 101: 277-348.

4. Godfrey DI, Berzins SP (2007) Control points in NKT-cell development. Nat Rev Immunol 7: 505-518. 
Citation: Subrahmanyam P, Wenji Sun, James East, Junxin Li and Tonya J Webb (2012) Natural Killer T Cell Based Immunotherapy. J Vaccines Vaccin 3:144. doi:10.4172/2157-7560.1000144

Page 6 of 9

5. Gumperz JE, Miyake S, Yamamura T, Brenner MB (2002) Functionally distinct subsets of CD1d-restricted natural killer T cells revealed by CD1d tetramer staining. J Exp Med 195: 625-636.

6. Kim CH, Johnston B, Butcher EC (2002) Trafficking machinery of NKT cells: shared and differential chemokine receptor expression among $\mathrm{V}$ alpha 24(+) $\checkmark$ beta $11(+)$ NKT cell subsets with distinct cytokine-producing capacity. Blood 100: $11-16$.

7. Lin H, Nieda M, Hutton JF, Rozenkov V, Nicol AJ (2006) Comparative gene expression analysis of NKT cell subpopulations. J Leukoc Biol 80: 164-173.

8. Ambrosino E, Terabe M, Halder RC, Peng J, Takaku S, et al. (2007) Crossregulation between type I and type II NKT cells in regulating tumor immunity: a new immunoregulatory axis. J Immunol 179: 5126-5136.

9. Griewank K, Borowski C, Rietdijk S, Wang N, Julien A, et al. (2007) Homotypic interactions mediated by Slamf1 and Slamf6 receptors control NKT cell lineage development. Immunity 27: 751-762.

10. Savage AK, Constantinides MG, Han J, Picard D, Martin E, et al. (2008) The transcription factor PLZF directs the effector program of the NKT cell lineage. Immunity 29: 391-403.

11. Kovalovsky D, Uche OU, Eladad S, Hobbs RM, Yi W, et al. (2008) The BTBzinc finger transcriptional regulator PLZF controls the development of invariant natural killer T cell effector functions. Nat Immunol 9: 1055-1064.

12. Alonzo ES, Sant'Angelo DB (2011) Development of PLZF-expressing innate T cells. Curr Opin Immunol 23: 220-227.

13. Calabi F, Milstein C (1986) A novel family of human major histocompatibility complex-related genes not mapping to chromosome 6. Nature 323: 540-543.

14. Moody DB, Porcelli SA (2003) Intracellular pathways of CD1 antigen presentation. Nat Rev Immunol 3: 11-22.

15. Barral DC, Brenner MB (2007) CD1 antigen presentation: how it works. Nat Rev Immunol 7: 929-941.

16. Cohen NR, Garg S, Brenner MB (2009) Antigen Presentation by CD1 Lipids, $T$ Cells, and NKT Cells in Microbial Immunity. Adv Immunol 102: 1-94.

17. Porcelli SA (2005) Bird genes give new insights into the origins of lipid antigen presentation. Proc Natl Acad Sci U S A 102: 8399-8400.

18. Koch M, Stronge VS, Shepherd D, Gadola SD, Mathew B, et al. (2005) The crystal structure of human CD1d with and without alpha-galactosylceramide. Nat Immunol 6: 819-826.

19. Zeng Z, Castaño AR, Segelke BW, Stura EA, Peterson PA, et al. (1997) Crysta structure of mouse CD1: An MHC-like fold with a large hydrophobic binding groove. Science 277: 339-345.

20. Kinjo Y, Ueno K (2011) iNKT cells in microbial immunity: recognition of microbial glycolipids. Microbiol Immunol 55: 472-482.

21. Brigl M, Brenner MB (2010) How invariant natural killer $T$ cells respond to infection by recognizing microbial or endogenous lipid antigens. Semin Immunol 22: 79-86.

22. Burdin N, Brossay L, Koezuka Y, Smiley ST, Grusby MJ, et al. (1998) Selective ability of mouse CD1 to present glycolipids: alpha-galactosylceramide specifically stimulates $\vee$ alpha 14+ NK T lymphocytes. J Immunol 161: 3271 3281.

23. Kawano T, Cui J, Koezuka Y, Toura I, Kaneko Y, et al. (1998) Natural killerlike nonspecific tumor cell lysis mediated by specific ligand-activated Valpha14 NKT cells. Proc Natl Acad Sci U S A 95: 5690-5693.

24. Seino K, Fujii S, Harada M, Motohashi S, Nakayama T, et al. (2005) Valpha14 NKT cell-mediated anti-tumor responses and their clinical application. Springer Semin Immunopathol 27: 65-74.

25. Carnaud C, Lee D, Donnars O, Park SH, Beavis A, et al. (1999) Cutting edge: cross-talk between cells of the innate immune system: NKT cells rapidly activate NK cells. J Immunol 163: 4647-4650.

26. Kinjo Y, Wu D, Kim G, Xing GW, Poles MA, et al. (2005) Recognition of bacterial glycosphingolipids by natural killer T cells. Nature 434: 520-525.

27. Sriram V, Du W, Gervay-Hague J, Brutkiewicz RR (2005) Cell wal glycosphingolipids of Sphingomonas paucimobilis are CD1d-specific ligands for NKT cells. Eur J Immunol 35: 1692-1701.

28. Mattner J, Debord KL, Ismail N, Goff RD, Cantu C 3rd, et al. (2005) Exogenous and endogenous glycolipid antigens activate NKT cells during microbial infections. Nature 434: 525-529.

29. Kinjo Y, Tupin E, Wu D, Fujio M, Garcia-Navarro R, et al. (2006) Natural killer T cells recognize diacylglycerol antigens from pathogenic bacteria. Nat Immunol 7: 978-986.

30. Kinjo Y, Illarionov P, Vela JL, Pei B, Girardi E, et al. (2011) Invariant natura killer T cells recognize glycolipids from pathogenic Gram-positive bacteria. Nat Immunol 12: 966-974.

31. Sada-Ovalle I, Chiba A, Gonzales A, Brenner MB, Behar SM (2008) Innate invariant NKT cells recognize Mycobacterium tuberculosis-infected macrophages, produce interferon-gamma, and kill intracellular bacteria. PLoS Pathog 4: e1000239.

32. Sada-Ovalle I, Sköld M, Tian T, Besra GS, Behar SM (2010) Alphagalactosylceramide as a therapeutic agent for pulmonary Mycobacterium tuberculosis infection. Am J Respir Crit Care Med 182: 841-847.

33. Emoto M, Yoshida T, Fukuda T, Kawamura I, Mitsuyama M, et al. (2010) Alphagalactosylceramide promotes killing of Listeria monocytogenes within the macrophage phagosome through invariant NKT-cell activation. Infect Immun 78: $2667-2676$

34. Emoto M, Emoto Y, Yoshizawa I, Kita E, Shimizu T, et al. (2010) Alpha-GalCer ameliorates listeriosis by accelerating infiltration of $\mathrm{Gr}-1+$ cells into the liver. Eur J Immunol 40: 1328-1341.

35. Wang H, Zhao L, Peng Y, Liu J, Qi M, et al. (2012) Protective role of a-galactosylceramide-stimulated natural killer $T$ cells in genital tract infection with Chlamydia muridarum. FEMS Immunol Med Microbiol 65: 43-54.

36. Joyee AG, Qiu H, Fan Y, Wang S, Yang X (2008) Natural killer T cells are critica for dendritic cells to induce immunity in Chlamydial pneumonia. Am J Respir Crit Care Med 178: 745-756.

37. Bharhani MS, Chiu B, Na KS, Inman RD (2009) Activation of invariant NKT cells confers protection against Chlamydia trachomatis-induced arthritis. Int Immunol 21: 859-870.

38. Bilenki L, Wang S, Yang J, Fan Y, Joyee AG, et al. (2005) NK T cell activation promotes Chlamydia trachomatis infection in vivo. J Immunol 175: 3197-3206.

39. Devera TS, Aye LM, Lang GA, Joshi SK, Ballard JD, et al. (2010) CD1d dependent B-cell help by NK-like $T$ cells leads to enhanced and sustained production of Bacillus anthracis lethal toxin-neutralizing antibodies. Infect Immun 78: 1610-1617.

40. Kulkarni RR, Haeryfar SM, Sharif S (2010) The invariant NKT cell subset in anti-viral defenses: a dark horse in anti-influenza immunity? J Leukoc Biol 88 : 635-643

41. Van Kaer L, Joyce S (2006) Viral evasion of antigen presentation: not just fo peptides anymore. Nat Immunol 7: 795-797.

42. Diana J, Lehuen A (2009) NKT cells: friend or foe during viral infections? Eur J Immunol 39: 3283-3291.

43. Sköld M, Behar SM (2003) Role of CD1d-restricted NKT cells in microbial immunity. Infect Immun 71: 5447-5455.

44. Grubor-Bauk B, Simmons A, Mayrhofer G, Speck PG (2003) Impaired clearance of herpes simplex virus type 1 from mice lacking CD1d or NKT cells expressing the semivariant $V$ alpha 14-J alpha 281 TCR. J Immunol 170: 1430-1434.

45. Sanchez DJ, Gumperz JE, Ganem D (2005) Regulation of CD1d expression and function by a herpesvirus infection. J Clin Invest 115: 1369-1378.

46. Renukaradhya GJ, Webb TJ, Khan MA, Lin YL, Du W, et al. (2005) Virusinduced inhibition of CD1d1-mediated antigen presentation: reciproca regulation by p38 and ERK. J Immunol 175: 4301-4308.

47. Lin Y, Roberts TJ, Spence PM, Brutkiewicz RR (2005) Reduction in CD1d expression on dendritic cells and macrophages by an acute virus infection. Leukoc Biol 77: 151-158

48. Roberts TJ, Lin Y, Spence PM, Van Kaer L, Brutkiewicz RR (2004) CD1d1 dependent control of the magnitude of an acute antiviral immune response. $J$ Immunol 172: 3454-3461.

49. Johnson TR, Hong S, Van Kaer L, Koezuka Y, Graham BS (2002) NK T cells contribute to expansion of CD8(+) T cells and amplification of antiviral immune responses to respiratory syncytial virus. J Virol 76: 4294-4303. 
Citation: Subrahmanyam P, Wenji Sun, James East, Junxin Li and Tonya J Webb (2012) Natural Killer T Cell Based Immunotherapy. J Vaccines Vaccin 3:144. doi:10.4172/2157-7560.1000144

50. Rao P, Pham HT, Kulkarni A, Yang Y, Liu X, et al. (2011) Herpes simplex virus 1 glycoprotein $B$ and US3 collaborate to inhibit CD1d antigen presentation and NKT cell function. J Virol 85: 8093-8104.

51. Webb TJ, Litavecz RA, Khan MA, Du W, Gervay-Hague J, et al. (2006) Inhibition of CD1d1-mediated antigen presentation by the vaccinia virus B1R and H5R molecules. Eur J Immunol 36: 2595-2600.

52. Yuan W, Dasgupta A, Cresswell P (2006) Herpes simplex virus evades natural killer $\mathrm{T}$ cell recognition by suppressing CD1d recycling. Nat Immunol 7: 835842.

53. Hage CA, Kohli LL, Cho S, Brutkiewicz RR, Twigg HL 3rd, et al. (2005) Human immunodeficiency virus gp120 downregulates CD1d cell surface expression. Immunol Lett 98: 131-135.

54. Chen N, McCarthy C, Drakesmith H, Li D, Cerundolo V, et al. (2006) HIV-1 down-regulates the expression of CD1d via Nef. Eur J Immunol 36: 278-286.

55. Reilly EC, Thompson EA, Aspeslagh S, Wands JR, Elewaut D, et al. (2012) Activated iNKT cells promote memory CD8+ T cell differentiation during viral infection. PLoS One 7: e37991.

56. Motsinger A, Haas DW, Stanic AK, Van Kaer L, Joyce S, et al. (2002) CD1drestricted human natural killer $T$ cells are highly susceptible to human immunodeficiency virus 1 infection. J Exp Med 195: 869-879.

57. Sandberg JK, Fast NM, Palacios EH, Fennelly G, Dobroszycki J, et al. (2002) Selective loss of innate CD4(+) $\vee$ alpha 24 natural killer $T$ cells in human immunodeficiency virus infection. J Virol 76: 7528-7534.

58. van der Vliet $\mathrm{HJ}$, von Blomberg BM, Hazenberg MD, Nishi N, Otto SA, et al. (2002) Selective decrease in circulating $V$ alpha $24+V$ beta $11+$ NKT cells during HIV type 1 infection. J Immunol 168: 1490-1495

59. Moll M, Kuylenstierna C, Gonzalez VD, Andersson SK, Bosnjak L, et al. (2009) Severe functional impairment and elevated PD-1 expression in CD1d-restricted NKT cells retained during chronic HIV-1 infection. Eur J Immunol 39: 902-911.

60. Courtney AN, Nehete PN, Nehete BP, Thapa P, Zhou D, et al. (2009) Alphagalactosylceramide is an effective mucosal adjuvant for repeated intranasal or oral delivery of HIV peptide antigens. Vaccine 27: 3335-3341.

61. Huang Y, Chen A, Li X, Chen Z, Zhang W, et al. (2008) Enhancement of HIV DNA vaccine immunogenicity by the NKT cell ligand, alpha-galactosylceramide. Vaccine 26: 1807-1816

62. Ishikawa H, Tanaka K, Kutsukake E, Fukui T, Sasaki H, et al. (2010) IFN-Y production downstream of NKT cell activation in mice infected with influenza virus enhances the cytolytic activities of both NK cells and viral antigen-specific CD8+ T cells. Virology 407: 325-332.

63. Paget C, Ivanov S, Fontaine J, Renneson J, Blanc F, et al. (2012) Interleukin-22 is produced by invariant natural killer T lymphocytes during influenza A virus infection: potential role in protection against lung epithelial damages. J Biol Chem 287: 8816-8829

64. Ko SY, Ko HJ, Chang WS, Park SH, Kweon MN, et al. (2005) alphaGalactosylceramide can act as a nasal vaccine adjuvant inducing protective immune responses against viral infection and tumor. J Immunol 175: 33093317.

65. Youn HJ, Ko SY, Lee KA, Ko HJ, Lee YS, et al. (2007) A single intranasal immunization with inactivated influenza virus and alpha-galactosylceramide induces long-term protective immunity without redirecting antigen to the central nervous system. Vaccine 25: 5189-5198.

66. Molling JW, Kölgen W, van der Vliet HJ, Boomsma MF, Kruizenga $\mathrm{H}$, et al. (2005) Peripheral blood IFN-gamma-secreting Valpha24+Vbeta11+ NKT cell numbers are decreased in cancer patients independent of tumor type or tumor load. Int J Cancer 116: 87-93.

67. Vivier E, Ugolini S, Blaise D, Chabannon C, Brossay L (2012) Targeting natura killer cells and natural killer T cells in cancer. Nat Rev Immunol 12: 239-252.

68. Kobayashi E, Motoki K, Uchida T, Fukushima H, Koezuka Y (1995) KRN7000, a novel immunomodulator, and its antitumor activities. Oncol Res 7: 529-534.

69. Nakagawa R, Serizawa I, Motoki K, Sato M, Ueno H, et al. (2000) Antitumor activity of alpha-galactosylceramide, KRN7000, in mice with the melanoma B16 hepatic metastasis and immunohistological study of tumor infiltrating cells. Oncol Res 12: 51-58

70. Schmieg J, Yang G, Franck RW, Tsuji M (2003) Superior protection against malaria and melanoma metastases by a C-glycoside analogue of the natural killer T cell ligand alpha-Galactosylceramide. J Exp Med 198: 1631-1641.

71. Giaccone G, Punt CJ, Ando Y, Ruijter R, Nishi N, et al. (2002) A Phase I study of the natural killer T-cell ligand alpha-galactosylceramide (KRN7000) in patients with solid tumors. Clin Cancer Res 8: 3702-3709.

72. Sullivan BA, Kronenberg M (2005) Activation or anergy: NKT cells are stunned by alpha-galactosylceramide. J Clin Invest 115: 2328-2329.

73. Uldrich AP, Crowe NY, Kyparissoudis K, Pellicci DG, Zhan Y, et al. (2005) NKT cell stimulation with glycolipid antigen in vivo: costimulation-dependen expansion, Bim-dependent contraction, and hyporesponsiveness to further antigenic challenge. J Immunol 175: 3092-3101.

74. Kim S, Lalani S, Parekh VV, Vincent TL, Wu L, et al. (2008) Impact of bacteria on the phenotype, functions, and therapeutic activities of invariant NKT cells in mice. J Clin Invest 118: 2301-2315.

75. Shibolet O, Alper R, Zlotogarov L, Thalenfeld B, Engelhardt D, et al. (2003) NKT and CD8 lymphocytes mediate suppression of hepatocellular carcinoma growth via tumor antigen-pulsed dendritic cells. Int J Cancer 106: 236-243.

76. Chung Y, Qin H, Kang CY, Kim S, Kwak LW, et al. (2007) An NKT-mediated autologous vaccine generates CD4 T-cell dependent potent antilymphoma immunity. Blood 110: 2013-2019.

77. Nieda M, Okai M, Tazbirkova A, Lin H, Yamaura A, et al. (2004) Therapeutic activation of Valpha24+Vbeta11+ NKT cells in human subjects results in highly coordinated secondary activation of acquired and innate immunity. Blood 103 383-389.

78. Ishikawa A, Motohashi S, Ishikawa E, Fuchida H, Higashino K, et al (2005) A phase I study of alpha-galactosylceramide (KRN7000)-pulsed dendritic cells in patients with advanced and recurrent non-small cell lung cancer. Clin Cance Res 11: 1910-1917.

79. Chang DH, Osman K, Connolly J, Kukreja A, Krasovsky J, et al. (2005) Sustained expansion of NKT cells and antigen-specific T cells after injection of alpha-galactosyl-ceramide loaded mature dendritic cells in cancer patients. $J$ Exp Med 201: 1503-1517.

80. Uchida T, Horiguchi S, Tanaka Y, Yamamoto H, Kunii N, et al (2008) Phase I study of alpha-galactosylceramide-pulsed antigen presenting cells administration to the nasal submucosa in unresectable or recurrent head and neck cancer. Cancer Immunol Immunother 57: 337-345.

81. Horiguchi S, Matsuoka T, Okamoto Y, Sakurai D, Kobayashi K, et al. (2007) Migration of tumor antigen-pulsed dendritic cells after mucosal administration in the human upper respiratory tract. J Clin Immunol 27: 598-604.

82. Nagato K, Motohashi S, Ishibashi F, Okita K, Yamasaki K, et al. (2012) Accumulation of Activated Invariant Natural Killer T Cells in the Tumo Microenvironment after $\alpha$-Galactosylceramide-Pulsed Antigen Presenting Cells. J Clin Immunol.

83. Barral P, Eckl-Dorna J, Harwood NE, De Santo C, Salio M, et al. (2008) B cell receptor-mediated uptake of CD1d-restricted antigen augments antibody responses by recruiting invariant NKT cell help in vivo. Proc Natl Acad Sci U S A105: 8345-8350.

84. Bosma A, Abdel-Gadir A, Isenberg DA, Jury EC, Mauri C (2012) Lipid-antigen presentation by $\mathrm{CD} 1 \mathrm{~d}(+) \mathrm{B}$ cells is essential for the maintenance of invariant natural killer T cells. Immunity 36: 477-490.

85. Metelitsa LS, Weinberg KI, Emanuel PD, Seeger RC (2003) Expression of CD1d by myelomonocytic leukemias provides a target for cytotoxic NKT cells Leukemia 17: 1068-1077.

86. Renukaradhya GJ, Khan MA, Vieira M, Du W, Gervay-Hague J, et al. (2008) Type I NKT cells protect (and type II NKT cells suppress) the host's innate antitumor immune response to a B-cell lymphoma. Blood 111: 5637-5645.

87. Exley M, Garcia J, Balk SP, Porcelli S (1997) Requirements for CD1d recognition by human invariant Valpha24+ CD4-CD8- T cells. J Exp Med 186: 109-120.

88. Nieda M, Nicol A, Koezuka Y, Kikuchi A, Lapteva N, et al. (2001) TRAlL expression by activated human CD4(+)V alpha 24NKT cells induces in vitro and in vivo apoptosis of human acute myeloid leukemia cells. Blood 97: 20672074.

89. Hix LM, Shi YH, Brutkiewicz RR, Stein PL, Wang CR, et al. (2011) CD1dexpressing breast cancer cells modulate NKT cell-mediated antitumor immunity in a murine model of breast cancer metastasis. PLoS One 6: e20702. 
Citation: Subrahmanyam P, Wenji Sun, James East, Junxin Li and Tonya J Webb (2012) Natural Killer T Cell Based Immunotherapy. J Vaccines Vaccin 3:144. doi:10.4172/2157-7560.1000144

90. Sriram V, Cho S, Li P, O'Donnell PW, Dunn C, et al. (2002) Inhibition of glycolipid shedding rescues recognition of a CD1+ T cell lymphoma by natura killer T (NKT) cells. Proc Natl Acad Sci U S A 99: 8197-8202.

91. Webb TJ, Li X, Giuntoli RL 2nd, Lopez PH, Heuser C, et al. (2012) Molecular Identification of GD3 as a Suppressor of the Innate Immune Response in Ovarian Cancer. Cancer Res 72: 3744-3752

92. Webb TJ, Giuntoli RL 2nd, Rogers O, Schneck J, Oelke M (2008) Ascites specific inhibition of CD1d-mediated activation of natural killer T cells. Clin Cancer Res 14: 7652-7658.

93. Wu DY, Segal NH, Sidobre S, Kronenberg M, Chapman PB (2003) Crosspresentation of disialoganglioside GD3 to natural killer T cells. J Exp Med 198 173-181.

94. Shimizu K, Kurosawa Y, Taniguchi M, Steinman RM, Fujii S (2007) Crosspresentation of glycolipid from tumor cells loaded with alpha-galactosylceramide leads to potent and long-lived T cell mediated immunity via dendritic cells. J Exp Med 204: 2641-2653.

95. Smyth MJ, Thia KY, Street SE, Cretney E, Trapani JA, et al. (2000) Differential tumor surveillance by natural killer (NK) and NKT cells. J Exp Med 191: 661668

96. Swann JB, Uldrich AP, van Dommelen S, Sharkey J, Murray WK, et al. (2009) Type I natural killer T cells suppress tumors caused by p53 loss in mice. Blood 113: 6382-6385

97. Nowak M, Arredouani MS, Tun-Kyi A, Schmidt-Wolf I, Sanda MG, et al (2010) Defective NKT cell activation by CD1d+ TRAMP prostate tumor cells is corrected by interleukin-12 with $\alpha$-galactosylceramide. PLoS One 5: e11311.

98. Bellone M, Ceccon M, Grioni M, Jachetti E, Calcinotto A, et al. (2010) iNKT cells control mouse spontaneous carcinoma independently of tumor-specific cytotoxic T cells. PLoS One 5: e8646.

99. Crowe NY, Coquet JM, Berzins SP, Kyparissoudis K, Keating R, et al. (2005) Differential antitumor immunity mediated by NKT cell subsets in vivo. J Exp Med 202: 1279-1288

100. Terabe M, Swann J, Ambrosino E, Sinha P, Takaku S, et al. (2005) A nonclassical non-Valpha14Jalpha18 CD1d-restricted (type II) NKT cell is sufficient for down-regulation of tumor immunosurveillance. J Exp Med 202 $1627-1633$

101. Motohashi S, Ishikawa A, Ishikawa E, Otsuii M, lizasa T, et al. (2006) A phase I study of in vitro expanded natural killer T cells in patients with advanced and recurrent non-small cell lung cancer. Clin Cancer Res 12: 6079-6086.

102. Kunii N, Horiguchi S, Motohashi S, Yamamoto H, Ueno N, et al. (2009) Combination therapy of in vitro-expanded natural killer $\mathrm{T}$ cells and alphagalactosylceramide-pulsed antigen-presenting cells in patients with recurrent head and neck carcinoma. Cancer Sci 100: 1092-1098.

103. Balato A, Unutmaz D, Gaspari AA (2009) Natural killer T cells: an unconventional T-cell subset with diverse effector and regulatory functions. J Invest Dermatol 129: 1628-1642.

104. Gober MD, Gaspari AA (2008) Allergic contact dermatitis. Curr Dir Autoimmun 10: 1-26.

105. Fukunaga A, Khaskhely NM, Ma Y, Sreevidya CS, Taguchi K, et al. (2010) Langerhans Cells Serve as Immunoregulatory Cells by Activating NKT Cells. J Immunol 185: 4633-4640.

106. Balato A, Unutmaz D, Gaspari AA (2009) Natural killer T cells: an unconventional T-cell subset with diverse effector and regulatory functions. J Invest Dermatol 129: 1628-1642.

107. Moodycliffe AM, Nghiem D, Clydesdale G, Ullrich SE (2000) Immune suppression and skin cancer development: regulation by NKT cells. Na Immunol 1: 521-525.

108. Nieuwenhuis EE, Gillessen S, Scheper RJ, Exley MA, Taniguchi M, et al. (2005) CD1d and CD1d-restricted iNKT-cells play a pivotal role in contact hypersensitivity. Exp Dermatol 14: 250-258.

109. Campos RA, Szczepanik M, Itakura A, Akahira-Azuma M, Sidobre S, et al (2003) Cutaneous immunization rapidly activates liver invariant Valpha14 NKT cells stimulating B-1 B cells to initiate T cell recruitment for elicitation of contact sensitivity. J Exp Med 198: 1785-1796.

110. Zhou L, Li K, Shi YL, Hamzavi I, Gao TW, et al. (2012) Systemic analyses of immunophenotypes of peripheral T cells in non-segmental vitiligo: implication of defective natural killer T cells. Pigment Cell Melanoma Res 25: 602-611.

111. Wu L, Van Kaer L (2009) Natural killer T cells and autoimmune disease. Cur Mol Med 9: 4-14.

112. van der Vliet HJ, von Blomberg BM, Nishi N, Reijm M, Voskuyl AE, et al. (2001) Circulating V(alpha24+) Vbeta11+ NKT cell numbers are decreased in a wide variety of diseases that are characterized by autoreactive tissue damage. Clin Immunol 100: 144-148.

113. Sharif S, Arreaza GA, Zucker P, Mi QS, Sondhi J, et al. (2001) Activation of natural killer $T$ cells by alpha-galactosylceramide treatment prevents the onse and recurrence of autoimmune Type 1 diabetes. Nat Med 7: 1057-1062.

114. Lehuen A, Lantz O, Beaudoin L, Laloux V, Carnaud C, et al. (1998) Overexpression of natural killer $T$ cells protects Valpha14- Jalpha281 transgenic nonobese diabetic mice against diabetes. J Exp Med 188: 1831 1839.

115. Baxter AG, Kinder SJ, Hammond KJ, Scollay R, Godfrey DI (1997) Association between alphabetaTCR+CD4-CD8- T-cell deficiency and IDDM in NOD/L mice. Diabetes 46: 572-582

116. Hammond KJ, Poulton LD, Palmisano LJ, Silveira PA, Godfrey DI, et al. (1998) alpha/beta-T cell receptor (TCR)+CD4-CD8- (NKT) thymocytes preven insulin-dependent diabetes mellitus in nonobese diabetic (NOD)/Lt mice by the influence of interleukin (IL)-4 and/or IL-10. J Exp Med 187: 1047-1056.

117. Wang B, Geng YB, Wang CR (2001) CD1-restricted NK T cells protec nonobese diabetic mice from developing diabetes. J Exp Med 194: 313-320.

118. Wilson SB, Kent SC, Patton KT, Orban T, Jackson RA, et al. (1998) Extreme Th1 bias of invariant Valpha24JalphaQ T cells in type 1 diabetes. Nature $391:$ $177-1781$.

119. Kent SC, Chen Y, Clemmings SM, Viglietta V, Kenyon NS, et al. (2005) Loss of IL-4 secretion from human type 1 a diabetic pancreatic draining lymph node NKT cells. J Immunol 175: 4458-4464.

120. Hong S, Wilson MT, Serizawa I, Wu L, Singh N, et al. (2001) The natural kille T-cell ligand alpha-galactosylceramide prevents autoimmune diabetes in nonobese diabetic mice. Nat Med 7: 1052-1056.

121. Hong J, Li N, Zhang X, Zheng B, Zhang JZ (2005) Induction of CD4+CD25+ regulatory $T$ cells by copolymer-I through activation of transcription factor Foxp3. Proc Natl Acad Sci U S A 102: 6449-6454.

122. Ly D, Mi QS, Hussain S, Delovitch TL (2006) Protection from type 1 diabetes by invariant NK T cells requires the activity of CD4+CD25+ regulatory $T$ cells. J Immunol 177: 3695-3704.

123. Rajavelu P, Rayapudi M, Moffitt M, Mishra A, Mishra A, et al. (2012) Significance of para-esophageal lymph nodes in food or aeroallergen-induced iNKT cellmediated experimental eosinophilic esophagitis. Am J Physiol Gastrointest Liver Physiol 302: G645-G654.

124. Thorburn AN, Foster PS, Gibson PG, Hansbro PM, et al. (2012) Components of Streptococcus pneumoniae Suppress Allergic Airways Disease and NKT Cells by Inducing Regulatory T Cells. J Immunol 188: 4611-4620.

125. Wingender G, Hiss M, Engel I, Peukert K, Ley K, et al. (2012) Neutrophilic Granulocytes Modulate Invariant NKT Cell Function in Mice and Humans. J Immunl 188: 3000-3008.

126. Satoh M, Andoh Y, Clingan CS, Ogura H, Fujii S, et al. (2012) Type II NKT Cells Stimulate Diet-Induced Obesity by Mediating Adipose Tissue Inflammation Steatohepatitis and Insulin Resistance. PLoS One 7: e30568.

127. Kerzerho J, Yu ED, Barra CM, Alari-Pahisa E, Girardi E, et al. (2012) Structura and Functional Characterization of a Novel Nonglycosidic Type I NKT Agonist with Immunomodulatory Properties. J Immunol 188: 2254-2265.

128. Wu L, Parekh VV, Gabriel CL, Bracy DP, Marks-Shulman PA, et al. (2012) Activation of invariant natural killer $T$ cells by lipid excess promotes tissue inflammation, insulin resistance, and hepatic steatosis in obese mice. Proc Natl Acad Sci U S A 109: E1143-E1152.

129. Liu Y, Luan X, Li J, He Y, Li M (2012) The role of invariant NKT cells in liver transplant tolerance in rats. Transplant Proc 44: 1041-1044.

130. Ikehara Y, Yasunami Y, Kodama S, Maki T, Nakano M, et al. (2000) CD4(+) Valpha14 natural killer $T$ cells are essential for acceptance of rat isle xenografts in mice. J Clin Invest 105: 1761-1767. 
Citation: Subrahmanyam P, Wenji Sun, James East, Junxin Li and Tonya J Webb (2012) Natural Killer T Cell Based Immunotherapy. J Vaccines Vaccin 3:144. doi:10.4172/2157-7560.1000144

131. Seino KI, Fukao K, Muramoto K, Yanagisawa K, Takada Y, et al. (2001) Requirement for natural killer T (NKT) cells in the induction of allograft tolerance. Proc Natl Acad Sci U S A 98: 2577-2581.

132. Hongo D, Tang X, Dutt S, Nador RG, Strober S, et al. (2012) Interactions between NKT cells and Tregs are required for tolerance to combined bone marrow and organ transplants. Blood 119: 1581-1589.

133. Hoffmann P, Ermann J, Edinger M, Fathman CG, Strober S (2002) Donortype CD4(+)CD25(+) regulatory T cells suppress lethal acute graft-versus-host disease after allogeneic bone marrow transplantation. J Exp Med 196: 389399.

134. Uhlig HH, Coombes J, Mottet C, Izcue A, Thompson C, et al. (2006) Characterization of Foxp3+CD4+CD25+ and IL-10-secreting CD4+CD25+ T cells during cure of colitis. J Immunol 177: 5852-5860.

135.Lan F, Zeng D, Higuchi M, Huie P, Higgins JP, et al. (2001) Predominance of NK1.1+TCR alpha beta+ or DX5+TCR alpha beta+ T cells in mice conditioned with fractionated lymphoid irradiation protects against graft-versus-host disease: "natural suppressor" cells. J Immunol 167: 2087-2096.

136.Zeng D, Lewis D, Dejbakhsh-Jones S, Lan F, García-Ojeda M, et al. (1999) Bone marrow NK1.1(-) and NK1.1(+) T cells reciprocally regulate acute graft versus host disease. J Exp Med 189: 1073-1081.
137. Hodge G, Hodge S, Li-Liew C, Reynolds PN, Holmes M (2012) Increased natural killer T-like cells are a major source of pro-inflammatory cytokines and granzymes in lung transplant recipients. Respirology 17: 155-163.

138. Hong S, Wilson MT, Serizawa I, Wu L, Singh N, et al. (2001) The natural killer T-cell ligand alpha-galactosylceramide prevents autoimmune diabetes in nonobese diabetic mice. Nat Med 7: 1052-1056.

139. Aspeslagh S, Li Y, Yu ED, Pauwels N, Trappeniers M, et al. (2011) Galactosemodified iNKT cell agonists stabilized by an induced fit of CD1d prevent tumour metastasis. EMBO J 30: 2294-2305.

140. Wun KS, Cameron G, Patel O, Pang SS, Pellicci DG, et al. (2011) A Molecular Basis for the Exquisite CD1d-Restricted Antigen Specificity and Functional Responses of Natural Killer T Cells. Immunity 34: 327-339.

141. Haeryfar SM, Lan Z, Leon-Ponte M, Duffy KR, et al. (2008) Prolongation of cardiac allograft survival by rapamycin and the invariant natural killer $\mathrm{T}$ cell glycolipid agonist OCH. Transplantation 86: 460-468.

142.Kuns RD, Morris ES, Macdonald KP, Markey KA, Morris HM, et al. (2009) Invariant natural killer T cell-natural killer cell interactions dictate transplantation outcome after alpha-galactosylceramide administration. Blood 113: 59996010 